\title{
Sweatshops and Free Action: The Stakes of the Actualism/Possibilism Debate for Business Ethics
}

\author{
Travis Timmerman ${ }^{1} \cdot$ Abe Zakhem ${ }^{1}$
}

Received: 18 September 2019 / Accepted: 15 February 2020

(c) Springer Nature B.V. 2020

\begin{abstract}
Whether an action is morally right depends upon the alternative acts available to the agent. Actualists hold that what an agent would actually do determines her moral obligations. Possibilists hold that what an agent could possibly do determines her moral obligations. Both views face compelling criticisms. Despite the fact that actualist and possibilist assumptions are at the heart of seminal arguments in business ethics, there has been no explicit discussion of actualism and possibilism in the business ethics literature. This paper has two primary goals. First, it aims to rectify this omission by bringing to light the importance of the actualism/possibilism debate for business ethics through questions about the ethics of sweatshops. Second, it aims to make some progress in the sweatshop debate by examining and defending an alternative view, hybridism, and describing the moral and practical implications of hybridism for the sweatshop debate.
\end{abstract}

Keywords Business ethics $\cdot$ Sweatshop $\cdot$ Actualism $\cdot$ Possibilism $\cdot$ Hybridism

\section{Introduction}

There is a consensus in normative ethics that the deontic status of an act depends upon the alternative acts available to the agent. Yet, there is a lack of consensus about which acts count as the relevant alternative acts available to an agent. It turns out that this is a surprisingly difficult question to answer, yet it's one on which any complete normative ethical theory must take a stance. It's also a question on which a number of issues in business ethics hinges. This issue can best be illustrated with a first-order case.

Entrepreneurial Eddie: Eddie the entrepreneur is opening a t-shirt factory today and now faces the following choice about what to pay his employees. He can pay them a low wage or he can pay them a high (i.e. living) wage. Suppose that the best thing Eddie can do over time is <pay his employees a high wage and keep the factory open as long as it's profitable $>$. However,

Travis Timmerman

Travis.Timmerman@shu.edu

Abe Zakhem

Abe.Zakhem@shu.edu

1 Seton Hall University, 400 South Orange Ave, South Orange, NJ 07079, USA because Eddie doesn't like sacrificing profit, he would freely decide to <close his factory after 6 months $>$ if he first $<$ pays his employees a high wage $>$. He would do this out of frustration in spite of the fact that the factory would be profitable. ${ }^{1}$ This would be the worst outcome. ${ }^{2}$ Alternatively, Eddie could $<$ pay his employees a low wage and keep the factory open as long as it's profitable>, which we can suppose is better than the worst outcome, yet worse than the best outcome. Finally, let's suppose that Eddie would freely decide to $<$ keep his factory open as long as it is profitable $>$ if today he decides to $<$ pay his employees a low wage $>$. ${ }^{3}$

${ }^{1}$ For the purposes of the debate, it doesn't matter why Eddie would close the factory after 6 months so long as he could keep it open. To keep things simple, we've just stipulated that he does it because he doesn't want to sacrifice profit. But the example could be amended to have him close it in response to market forces, acquiring different entrepreneurial interests, fatigue or anything else.

2 There may be a variety of reasons that it's worse for people to receive a high pay for 6 months and then become unemployed than to not receive the job in the first place. Let's suppose that being temporarily lifted out of extreme poverty would result in them incurring other financial commitments they'll be unable to meet once they're unemployed again, and that this will leave them worse off than before.

3 This case is structurally similar to an example proposed by Goldman (now Holly Smith) (1978, pp. 185-186). Variations of this example appear throughout the literature, including in Jackson and Pargetter (1986, p. 235), Carlson (1995, p. 124), Vorobej (2000, pp. 131-132), Portmore (2011, p. 180; 2019, chap. 5), Timmerman 
To be sure, Eddie can choose to pay his employees a high wage when the factory opens and, 6 months down the road, he can choose to keep his factory open as long as it is profitable. The problem is simply that Eddie would freely choose to $<$ close the factory after 6 months $>$ if he today chooses to $<$ pay his employees a high wage $>$. Furthermore, we can suppose that Eddie would make this choice no matter what his intentions are today.

Here is the tricky ethical question. In light of these facts, is Eddie obligated to pay his employees a high wage? Roughly, actualists hold that Eddie is obligated to pay his employees a low wage because what would actually happen if he pays them a low wage is better than what would actually happen if he pays them a high wage. Possibilists, however, hold that Eddie is obligated to pay his employees a high wage because doing that is part of the best series of acts that it's possible for Eddie to perform, viz. pay his employees a high wage and keep the factory open as long as it's profitable. Both actualism and possibilism have some intuitive appeal, yet (as will be illustrated shortly) both are subject to seemingly quite compelling objections. ${ }^{4}$

Here's the rub for business ethics. One can find, and construct, structurally analogous cases for any applied business ethics question. ${ }^{5}$ Surprisingly, however, there has been no explicit discussion of actualism and possibilism in the business ethics literature, though numerous papers contain arguments that either inadvertently commit their authors to one of these views, or at least strongly suggest that they are disposed to accept one of these views. The purpose of this paper is twofold. First, it aims to rectify this omission in the literature by bringing to light the importance of the actualism/

\section{Footnote 3 (continued)}

(2015, p. 1512), Timmerman and Cohen (2016, pp. 673-674), and Cariani (2016, p. 400).

${ }^{4}$ As is standard in the literature, we formulate actualism and possibilism in terms of one's objective, rather than one's subjective, obligations. Roughly, an objective obligation is what an agent should do if she were aware of all of the normatively relevant facts. Subjective obligations, by contrast, are determined by the agent's epistemic state (such as her beliefs, or beliefs that would be supported by her evidence) concerning the normatively relevant facts (cf. Portmore 2011, pp. 12-23; Zimmerman 1996, pp. 10-20). To keep the dialectic as simple as possible, unless we state otherwise, we'll assume that the agents in the cases we give know all of the normatively relevant facts. This means that the agent's subjective and objective obligations are identical in such cases. But nothing important, for the purposes of our argument, hangs on this assumption. Since agents never have full knowledge of how they would act in various counterfactual situations, the real life application of these views requires agents to act in light of the best evidence they have about how they would freely act in such situations.

5 This includes, for instance, questions about manipulative advertising practices (Holley 1998; Arrington 1982), payday loans (Mayer 2003; Stegman 2007), stakeholder theory (Zakhem 2008), and CEO pay (Moriarty 2009). possibilism debate for business ethics. It will primarily do so by examining the debate through questions about the ethics of sweatshops. Second, it aims to make some progress in the sweatshop debate by (i) illustrating how both actualist and possibilist assumptions underlie existing arguments in the sweatshop literature and by (ii) defending an alternative view to actualism and possibilism, viz. hybridism. This alternative view has direct moral and practical import for the ethics of sweatshops. If hybridism is correct, it provides reason to think that it's almost always morally wrong for individuals (and companies) to create sweatshops, though they may nevertheless, under certain specific conditions, have most moral practical reason to create them. This is a view that has not yet been defended in the literature. ${ }^{6}$

This paper is structured as follows. In the next section, we provide a more detailed overview of actualism and possibilism, and review the most salient ethical implications for the sweatshop debate. In the third section, we provide a brief overview of the literature on sweatshops, showing that actualist and possibilist assumptions underlie (or are at least suggested by) some arguments made in the literature and demonstrate that there is no way to fully resolve the sweatshop debate without first taking a stance on the actualism/possibilism debate. After that, we argue that neither a purely actualist nor a purely possibilist view on the ethics of sweatshops is viable. In the space we have left, we provide a prima facie defense of our favored hybridist position and, in doing so, discuss the implications of our view for the sweatshop debate.

\section{Actualism, Possibilism, and Sweatshops}

Now that we have provided a basic overview of the actualism/possibilism debate, we are in a position to examine each position in more detail and explain their implications for the sweatshop debate. We'll start with actualism.

\section{Actualism}

Should Eddie pay his employees a low or high wage? Since we've already provided a cursory explanation of the two

\footnotetext{
${ }^{6}$ The actualism/possibilism debate concerns the relationship between agents' free actions and their moral obligations at either the group or the individual level. For the sake of simplicity, our discussion will focus on the debate at the level of individual obligations. So, we'll proceed as if individual agents, rather than group agents, are responsible for the creation and conditions of sweatshops. However, nothing important for the purposes of our argument hangs on our describing the problems in these terms. Everything we write about individual obligations applies, mutatis mutandis, at the level of group obligations as well.
} 
primary views in the literature, we are now in a position to examine each of them more closely. Let's start with actualism, which may be defined more precisely as follows.

Actualism: At $t$ an agent $S$ morally ought to $\varphi$ at $t$ ' iff $\varphi$-ing at $t^{\prime}$ is an act-set currently under $S$ 's control at $t$, and what would happen if $S$ were to $\varphi$ at $t^{\prime}$ is better $^{7}$ than what would happen if $S$ were to perform any incompatible maximally specific act-set ${ }^{8}$ under $S$ 's control at $t .^{9}$

In other words, actualists hold that at any given time one should perform the most precise act-set under their control at that time that, if performed, would result in the best outcome. In the case of Eddie, then, the actualist holds that he should < pay his employees a low wage $>$ because, given what is under his control today, paying his employees a low wage is the act that would result in the best outcome. At the time the factory opens, the actualist does not even regard $<$ paying the employees a high wage and keeping the factory open $>$ as a relevant option for Eddie, even though they grant that this is something he can do. ${ }^{10}$ So, for all intents and purposes, actualists treat their future selves as completely distinct agents whenever the agent's future self in not under the agent's present control.

If true, actualism would seem to have important, and rather drastic, implications for the ethics of sweatshops.

\footnotetext{
7 To avoid assuming impartial consequentialism, this sense of better may be understood to be tracking deontic value instead of intrinsic value.

${ }^{8}$ At $t$, a maximally specific act-set that an agent can perform is one that extends from $t$ to the last moment of time at which the agent can perform an act.

${ }^{9}$ Unlike this formulation of actualism, early formulations did not build in a control condition. See Sobel (1976) and Jackson and Pargetter (1986). Here is one such formulation. Actualism: At $t$ an agent $S$ is obligated to $\varphi$ at $t^{\prime}$ iff $S$ can $\varphi$ at $t^{\prime}$ and what would happen if $S$ were to $\varphi$ at $t^{\prime}$ is better than what would happen if $S$ were to $\sim \varphi$ at $t^{\prime}$. These versions of actualism are subject to devastating problems. Most notably, they violate the principle of normative inheritance (Portmore 2019, chap. 4) and they generate conflicting obligations without saying which obligation takes priority. See Cohen and Timmerman (2016, pp. 11-12), Kiesewetter (2015, pp. 929-934), and Portmore (2011, pp. 181-183). Subsequent versions of actualism built in a control condition to avoid this problem. See, for instance, Goldman (1978, p. 202), Bykvist (2002, pp. 61-64), and Jackson (2014). Given this definition, Douglas Portmore's (2011) and Ross's (2013) securitist views also count as versions of actualism.

10 After all, by stipulation, Eddie can now decide to < pay his employees a high wage $>$. If he does this, then by stipulation, 6 months down the road, he can decide to <keep the factory open as long as it's profitable $>$. If an agent can $<A>$ and if they can $\langle B>$ if they first $<\mathrm{A}>$, then the agent can $<\mathrm{A} \& \mathrm{~B}>$. So, to be clear, actualists and possibilists may agree with one another about which act-sets agents can perform in any given case. Their disagreement concerns which acts, from among the acts the agent can perform, are normatively relevant options for the agent.
}

Most notably, it would vindicate the creation of sweatshops in certain cases when the alternative would make potential workers even worse off (e.g. when they would not be employed at all). This is interesting because it stands in stark contrast to the perceived wisdom in the early literature on the ethics of sweatshops ${ }^{11}$ and is in tension with the current anti- "exploitation" arguments against sweatshops. ${ }^{12}$ Notably, it also stands in contrast to the so-called Reasonable View in the literature, which holds that it's permissible for consumers to purchase goods from sweatshops since that is the most they can do to benefit the workers, but impermissible for employers to create sweatshops because they could pay their workers a high wage. ${ }^{13}$ If actualism is true, then the actions of both sweatshop employers and consumers of sweatshop goods may be vindicated. This is also interesting because, while not exactly identical, it is in line with a number of arguments in the literature that justify sweatshops that are the product of consensual, mutually beneficial transactions. ${ }^{14}$ If true, actualism would be welcome news for those who wish to defend the permissibility of sweatshops full stop.

\section{Possibilism}

Now let's examine possibilism in more detail, which may be defined precisely as follows.

Possibilism: At $t$ an agent $S$ is obligated to $\varphi$ at $t^{\prime}$ iff $\varphi$-ing at $t^{\prime}$ is part of the best series of acts that $S$ can perform from $t$ to the last moment that $S$ can perform possibly perform an act.

In other words, possibilists hold that, at any given time, an agent is obligated to perform the act that is part of the best series of acts that she can perform over the course of her life. Moreover, they hold that agents ought to do this irrespective of how they would act in the future if they performed the act in question. So, possibilists hold that Eddie is obligated to $<$ pay his employees a high wage $>$ in virtue of his supposed

\footnotetext{
11 See, for instance, Maitland (1996).

12 See, for instance, Arnold (2003), Arnold and Bowie (2003), Mayer (2007), Meyers (2004, p. 327, 2007), Snyder (2008, 2009, 2010), Steiner (1984), and Wertheimer (1999).

13 For discussion, see Faraci (2019).

${ }^{14}$ Such arguments generally appeal what's called the non-worseness claim, which will be discussed in the next section. Zwolinski (2008, p. 2007) has done the most to defend this sort of argument. See also Powell and Zwolinksi (2012) and Ferguson (2016). Though, it's worth explicitly noting that Zwolinksi's concern is that external market factors will undermine the viability of the sweatshop, not that the owner of the sweatshop will decide to close their business because it's not maximizing profits. For some criticisms of this style of argument, see Malmqvist (2017, 2013) and Barnes (2013).
} 
obligation to both $<$ pay his employees a high wage and keep the factory open $>$, which they regard as a relevant option for Eddie. ${ }^{15}$ Possibilists, then, treat their future selves in the same way they treat their present selves. They regard their future selves as importantly distinct from other agents over which they also (at the present time) lack control.

As Entrepreneurial Eddie makes clear, possibilism is generally much more demanding of imperfect agents than actualism since possibilism requires agents to bring about the best outcome they can irrespective of the free (akratic or immoral) choices they would make in the future. ${ }^{16}$ If true, possibilism would also have important, and rather drastic, implications for the ethics of sweatshops. Most obviously, employers may be obligated to pay their workers high wages even at the expense of high profit margins. It would generally be morally wrong to create sweatshops when the employers could pay their workers a higher wage than they do, even if the workers' wage is the product of consensual, mutually beneficial transactions. More generally, employers and consumers may be obligated to perform beneficent acts, and not merely non-harmful ${ }^{17}$ ones. If possibilism is true, then the most popular and influential moral defenses of sweatshops may fail. This would be welcome news for those who wish to justify their intuitive judgments that sweatshop employers are doing something morally wrong.

In this section, we've reviewed actualism and possibilism in detail and highlighted the important implications of each view for the sweatshop debate. This raises the question of whether the ethicists who have contributed to the sweatshop literature are actualists, possibilists, or neither. In the next section, we examine what we take to be the seminal arguments in the contemporary literature on sweatshops and show how some arguments inadvertently presuppose (and others merely suggest) actualist assumptions, while others

\footnotetext{
15 Possibilists then assume a principle of deontic logic known as "ought distributes through conjunction." This principle holds that if an agent $S$ ought to do both A and B, then $S$ ought to do A and $S$ ought to do $\mathrm{B}$. This principle is represented in the standard deontic logic system as follows: $\mathrm{O}(\mathrm{A} \& \mathrm{~B}) \rightarrow \mathrm{O}(\mathrm{A}) \& \mathrm{O}(\mathrm{B})$. Versions of actualism that build in a control condition are consistent with this principle, while versions of actualism that don't are inconsistent with this principle.

16 There are exceptions, however. Actualism might require certain agents to make demanding sacrifices now (e.g. doing something unpleasant to develop a more altruistic character) in order to ensure that they do more good in the future. Possibilism, by contrast, wouldn't require such sacrifices. For discussion on the demandingness of actualism versus possibilism, see Timmerman (2019) and Timmerman and Swenson (2019).

17 Here harm should be understood to pick out the counterfactual comparative account of all things considered harm, which is the account of harm that seems to be assumed in the literature. For a discussion of this type of harm, see Timmerman (2016).
}

inadvertently presuppose (and others merely suggest) possibilist assumptions. ${ }^{18}$

\section{Business Ethicists on Sweatshops}

In this section, we start by providing a rather brief and general overview of some important articles in the literature, while also focusing on certain crucial moves that appear throughout a number of articles, and which deserve special attention.

\section{Arguments that are Possibilist in Spirit}

Perhaps the primary question about the ethics of sweatshops concerns whether employers (or companies) are morally obligated to provide wages above what local market conditions and employment transactions dictate. Or, as we've simplistically put the question up until now, should employers pay their employees a "high" wage? Those who have answered in the affirmative generally provided the following sorts of reasons in favor of their view. Though sweatshop laborers generally voluntarily and, at times, enthusiastically accept and benefit from the low wages provided, these laborers are nevertheless exploited when their wages fall below a morally acceptable minimum. Employers (and companies) arguably generally have the requisite knowledge and power to provide "high" wages (Arnold and Bowie 2003). Additionally, it is possible for companies to pay a high wage without making the situation morally worse. Indeed, higher wages can often make the situation morally better if continued high wages are accompanied by other sorts of actions. For instance, some conceive of a more just economy where market failures are not rewarded (Arnold and Hartman 2005). Others argue that it is possible for companies to efficiently absorb and spread out the costs of higher wages in various ways, such as limiting short-term profits. They also point out that there are good reasons to believe that increasing wages could, in certain conditions created by the owner, lead to (i) increased worker productivity, (ii) a positive marketing campaign, and (iii) ultimately increase longterm value production (Meyers 2004).

There are a variety of arguments in the sweatshop literature that are possibilist in spirit. Many, though not all, are unified by the idea that sweatshop employers wrongfully

\footnotetext{
18 Some arguments are also, in a sense, underspecified and not committed to one view in the actualist/possibilist debate. However, in order to provide a fully robust defense of their view, they would have to take a stance on the debate.
} 
exploit their employees in a way that is morally wrong. ${ }^{19}$ Exploitation may be thought to occur when the employer takes advantage of the employee by benefitting disproportionately from the product they together create (Meyers 2004, p. 327). This would be an instance of wrongful exploitation because the disproportionate benefit is supposedly unfair (Snyder 2010, p. 188) ${ }^{20}$ Importantly, this exploitation is thought to be unfair even in cases in which both the employee and employer consent to the transaction, there are no negative externalities, and the arrangement makes both the employee and employer better off. David Faraci (2019) nicely captures this idea when explaining how this position is consistent with both deontological and consequentialist views. He first considers a principle he refers to as D2, and which we'll refer to as Unfair Distribution.

Unfair Distribution: It is impermissible to distribute gains in welfare unfairly, unless fair distribution is impossible or otherwise impermissible (p. 176).

Faraci holds that employers have the option of consistently paying employees a high wage even though they wouldn't do so if they were to start a sweatshop. On the other hand, in defense of the so-called Reasonable View, Faraci holds that it's permissible for third parties to support sweatshops because they can't ensure "that [the employee] is hired and compensated" with a high wage (p. 176). Of course, the employer can ensure as much, so Faraci holds that employers are obligated to ensure that that their employees are consistently paid a high wage irrespective of how they would act in the relevant counterfactual situations.

Notice that each of these arguments focuses on what it's possible for employers (and companies) to do. Each argument entails that employers are obligated to continually pay their employees high wages independent of what employers (and companies) would otherwise do. As such, these arguments appear possibilist in nature. Though none of these authors explicitly commit themselves to possibilism, they inadvertently do so by (*) assuming that it's a relevant option for employers (and companies) to continually pay their workers a high wage, and $(* *)$ by arguing that employers are obligated to bring about this optimal outcome.

\footnotetext{
19 See, for instance, Arnold and Bowie (2003), Faraci (2019), Meyers (2004), Sample (2003), Steiner (1984), Valdman (2008, 2009), and Wertheimer (1999).

${ }^{20}$ Snyder $(2008,2010)$ also considers Kantian exploitation of using others as a mere means. For other heavily Kantian-esque critiques, see Bowie (1999), Hill (2002), Herman (2007), and Radin and Calkins (2006). We don't focus on Kantian critiques (or the Kantian aspects of the exploitation arguments) cited in this paper. Instead, our primary focus is on the broader, more theoretically neutral, exploitation arguments against sweatshops.
}

\section{Arguments that are Actualist in Spirit}

By contrast, those who have argued that companies ought not to raise wages above what markets dictate approach the question from a different angle. They seem to think that the central question as to what employers (and companies) ought to do turns on what would actually happen to sweatshop workers if they're employed at a low wage compared to what would actually happen to them if they weren't (Maitland 2001). They grant that it is certainly possible for a company to raise wages above what the market dictates, and some even grant that this would be better were employers (and companies) to do it. At the same time, they'll highlight the fact that businesses operate in a very competitive environment. Ceteris paribus, those who actually raise wages will be at a competitive disadvantage. If the employer does raise wages, they may then later decide to compensate for this lost profit opportunity (e.g. by significantly reducing wages, downsizing, or making other substantial cutbacks). ${ }^{21}$ The underlying thought behind these sorts of arguments seems to be that while it's possible (perhaps in ideal circumstances) for employers to continually pay their employees a high wage, they're permitted to pay them a low wage because, if they didn't, the workers would be even worse off. This could be because the potential employees wouldn't have jobs in the first place, because consumers may then favor companies that pay the higher wages, hurting the worse-off workers, or because paying them a high wage would result in some other worse downstream effects. These problems help illustrate why some believe that paying workers the low wage dictated by the market is morally permissible. The basic thought is that it's permissible when it's preferable to what otherwise would happen. ${ }^{22}$ Since each of these arguments focuses on the counterfactual question of how the sweatshop employees would fare were they not to be paid a low wage, such arguments appear actualist in nature. Though, notably, not every counterfactual consideration concerns the sweatshop owners' future self and akrasia, and not all considerations fit the structure of Entrepreneurial Eddie, which is but one

\footnotetext{
${ }^{21}$ One complication is that paying a high wage can result in a loss of market share and can sometimes ultimately cause the company to go out of business, only to be replaced by other companies that would be even more exploitative. This shows that questions about the ethics of sweatshops don't only hinge on answers to questions about the actualism/possibilism debate, but also on questions about collective action problems. For discussion of this issue in other contexts, see Kagan (2011) and Nefsky (2011) for a reply. The structural and collective action problems in markets can make the discretionary action of individual agents or companies ineffective or at worst detrimental (Mayer 2007).

22 Along similar lines, some have argued that companies may even be morally justified in breaking the law if doing so is more attractive than any other available option (Powell and Zwolinski 2012).
} 
example in the actualism/possibilism debate. Nevertheless, although none of these authors explicitly commit themselves to actualism, they inadvertently do so when they appeal to such counterfactual questions in assessing the permissibility of paying workers a low wage.

There are also a variety of arguments in the sweatshop literature that appear actualist in spirit, even if they do not necessarily commit the authors to actualism. Many, though not all, are unified by an appeal to the non-worseness claim, which is formulated as follows.

Non-worseness Claim: It cannot be morally worse for A to interact with B than it is for A not to interact with $\mathrm{B}$ when the interaction is mutually beneficial, consensual, and free from negative externalities (Powell and Zwolinski 2012, p. 469). ${ }^{23}$

While the non-worseness claim is consistent with rejecting actualism, note that what is generally assumed to determine whether the interaction is beneficial is whether the agents in question would be better off if the transaction occurred than if it did not. It is this assumption, combined with the non-worseness claim, that makes such defenses in the literature appear actualist in nature. To illustrate, consider a case where sweatshop employees consent to work for low wages and imagine that there are no negative externalities that result from their employment. If, as it is assumed in the literature, it's permissible for potential sweatshop employers to not hire the sweatshop employees in the first place and if, as it is assumed in the literature, sweatshop employees freely chose to work and are better off working than they would otherwise be ${ }^{24}$ the non-worseness claim entails that employers and employees are both acting permissibly. This is but one of many examples that can be constructed to illustrate the same point.

What's interesting is that pro-sweatshop arguments that appeal to the non-worseness claim are thought to provide a theory neutral defense of sweatshops (Faraci 2019). In one sense, this is true. After all, such arguments are consistent with various versions of deontology, consequentialism, contractualism, and virtue ethics. In another sense, however, they aren't theory neutral because they appear to be actualist in nature. Though none of these authors explicitly commit themselves to actualism, they inadvertently do so once they assume that the permissibility of creating sweatshops depends, in part, on how well of sweatshop employees would otherwise fare.

\footnotetext{
${ }^{23}$ See also Barnes (2013, p. 159), Faraci (2019, p. 2), Snyder (2009), Zwolinski's (2007, pp. 708-710; 2008, pp. 357-360), and Wertheimer (1999, pp. 289-293).

${ }^{24}$ For arguments that sweatshop workers do not receive a net benefit from their employment, or did not freely choose to be employed, see Arnold (2001), Kates (2015), and Miller (2003).
}

To be clear, possibilists and actualists can agree that $<$ paying employees a high wage and keeping the factory open as long as it is profitable $>$ is the optimal situation, though not everyone even agrees about this. Since companies and their respective management teams can continually pay their employees a high wage, possibilists conclude that they are obligated to do so, so long as this is what would bring about the best outcome. This seems to have a certain degree of intuitive appeal and, as we've seen, many business ethicists seem to be in this camp. Although receiving a high wage is theoretically optimal, given how well sweatshop employees would otherwise fare, actualists conclude that companies (or employers) are not obligated to provide such a wage. Indeed, they shouldn't if it will only make employees worse off in the long run. Both actualist and possibilist positions seem to have a degree of intuitive appeal. As we will argue in the next section, however, there is good reason to believe that both actualist and possibilist views are false.

\section{Where Actualist and Possibilist Arguments Go Wrong}

What seems paradoxical about the actualism and possibilism debate is that both of these mutually exclusive views seem to be getting at something important and true. Moreover, as we will argue shortly, both views also seem to be committed to deeply implausible claims. In this section we reveal the implausible commitments of each position, both generally and specifically with respect to the sweatshop debate. ${ }^{25}$ Then, in the final section, we use the lessons to be gleamed from actualism's and possibilism's shortcomings to motivate an alternative view, viz.- - hybridism, and explore its implications for the sweatshop debate.

\section{What's Wrong with Possibilism?}

Possibilism is subject to one particularly difficult objection. Since facts about how agents would freely act in the future plays no role in determining possibilism's verdicts, it generates action-guiding obligations that, if acted on, would result in the worst possible outcome. We can state the objection more precisely as follows.

The Worst Outcome Objection: Possibilism entails that an agent $S$ can have an action-guiding obligation to $\varphi$ even when $\varphi$-ing entails that $S$ would perform an

\footnotetext{
${ }^{25}$ For a very detailed overview of all of the important objections to actualism and possibilism, ones that go beyond the scope of this paper, see Timmerman and Cohen (2019, Sects. 2.5, 3.4, and 3.5).
} 
act-set that is deeply morally wrong and that is worse than the act-set $S$ would perform if $S$ were to $\sim \varphi .^{26}$

This consequence is especially unpalatable in cases where the difference is goodness between the best and second best outcome is slight, yet the difference between the second best and worst outcome is large. For instance, consider a variation of Entrepreneurial Eddie, where the potential employees are in especially dire straits and whose only hope of being lifted out of extreme poverty is to find steady employment. As before, if Eddie were to <pay his employees a high wage $>$, he would $<$ close the factory after 6 months $>$ failing to lift anyone out of extreme poverty. However, now let's suppose that if Eddie were to <pay his employees a very near high wage ${ }^{27}>$, he would $<$ keep the factory open as long as it's profitable $>$, which we can assume will permanently lift everyone out of poverty, significantly improving their lives. Possibilism entails that Eddie should now choose to pay his employees the ever so slightly higher wage even though, no matter what else he intends to do now, this would result in complete disaster for all of his employees. Possibilism entails this even though Eddie could now choose to pay his employees something very near a high wage, which would result in a near optimal outcome for everyone.

The problem gets worse if it is additionally assumed (as it often is in possibilist exploitation arguments) ${ }^{28}$ that it's permissible for the employee to not hire anyone in the first place. If possibilism is true, Eddie could reason as follows. "If I open a factory, I'll do something wrong (i.e. pay people just below the morally acceptable salary). If I don't open a factory, I won't do anything wrong. I don't want to do anything wrong, so I won't open a factory." But now everyone is worse off as a result, so something seems to have gone wrong. ${ }^{29}$ How could morality prohibit an action that is better for everyone and worse for no one, while permitting an alternative action that is worse for everyone and better for no one? This consideration has lead Arneson (2013) and McMahan (2018) to hold that it must be acceptable for Eddie to pay his employees less than a high wage. Others, such as Pummer (2019), have tried to avoid this problem by endorsing something roughly in the vein of hybridism, which will

\footnotetext{
26 This objection is raised in Goldman (1976, pp. 469-70), Woodard (2009, pp. 219-220), Portmore (2011, p. 211), and Timmerman and Cohen (2016, p. 674).

27 Take whatever the minimally morally acceptable wage is and suppose that its one cent less than that. If the boundaries for a morally acceptable wage are vague, then suppose it is one cent less than the smallest wage that is indeterminately neither acceptable nor unacceptable.

${ }^{28}$ Every paper we've cited that discusses the non-worseness claims make this assumption.

${ }^{29}$ For further discussion of this problem, see Horton (2017, 2019), McMahan (2018), and Pummer (2019).
}

be discussed in Sect. 4.3. Everyone, however, should want to avoid the possibilist conclusion that Eddie has an actionguiding moral obligation to act in a way that will bring about the worst possible outcome.

\section{What's Wrong with Actualism?}

Actualism's verdicts are determined, in part, by how agents would freely act in the future, and so they avoid the Worst Outcome Objection. However, actualism is subject to two distinct, comparably troubling, objections. First, and most straightforwardly, actualism allows agents to avoid incurring obligations when they're disposed to behave badly. But agents shouldn't get out of having to do good things because they're disposed to do bad things. This objection may be formulated more precisely as follows.

The Not Demanding Enough Objection: Actualism permits an agent $S$ to avoid incurring any moral obligation to $\varphi$, which $\mathrm{S}$ can easily fulfill, in virtue of $S$ 's rotten moral character. ${ }^{30}$

This consequence is especially unpalatable in cases where the difference is goodness between the best and second best outcome is very large, yet the difference between the second best and worst outcome is very small. To illustrate, consider another variation of Entrepreneurial Eddie. This time Eddie has the opportunity to vastly improve working conditions in ways that would save many lives at the expense of losing mere pennies in profit a month. However, were Eddie to agree to this opportunity, let's suppose he would later become angry at the thought of losing profit and cancel the changes just before they take place. This would be worse than turning down the changes from the get-go because Eddie would get his employee's hopes up if he first agrees to the changes, and then prevents them from taking place. According to actualism, Eddie avoids incurring an obligation to improve working conditions simply because he is disposed to later prevent those very changes. But this seems to be an implausible result. Agents' dispositions to do wrong shouldn't allow them to avoid incurring obligations to do good.

Not only does actualism allow agents to avoid incurring obligations to do good, but it can also sanction bad behavior, requiring agents to perform seemingly terrible acts. We can formulate this objection more precisely as follows.

The Bad Behavior Objection: Actualism prescribes bad behavior, and acting on such prescriptions pre-

\footnotetext{
30 This objection is raised in Jackson and Pargetter (1986, p. 240), Zimmerman (2006, p. 156), Portmore (2011, p. 207), Baker (2012, pp. 642-3), and Timmerman (2015, pp. 1512-1513).
} 
sumably renders ${ }^{31}$ an agent $S$ immune from moral criticism, even when $S$ can easily refrain from such behavior. $^{32}$

To see why actualism has this implication, imagine a rather graphic variation of the Entrepreneurial Eddie example. Suppose that Eddie is prone to fits of rage when he thinks his employees aren't working hard enough. If Eddie murders an employee in a fit of rage tonight, he'll calm his nerves and murder no one tomorrow. However, if he bypasses the chance to murder anyone tonight, he'll decide to murder two of his employees tomorrow. ${ }^{33}$ Actualism entails that Eddie is obligated to murder one of his employees tonight, which clearly seems to be the wrong result. Notice that actualism has this implication even though Eddie can refrain from murdering anyone by first choosing to refrain from committing murder tonight and, once tomorrow rolls around, again choosing to refrain from committing murder.

It's worth noting that Powell and Zwolinski (2012) consider a similar sort of case when they consider objections to their (actualist-esque) defense of sweatshops. They imagine someone in a boat offering to rescue another drowning person for the sum of $\$ 10,000$ (p. 466). If the person in the boat would otherwise let the person drown, as is assumed in Powell and Zwolinski's example, actualism entails that they are obligated to extort $\$ 10,000$ from the drowning person. Interestingly, Powell and Zwolinski wish to avoid this conclusion and hold that the rescuer is obligated to save the drowning person because, in demanding $\$ 10,000$ for a simple rescue mission, they're "taking wrongful advantage" of their monopoly on the means of rescue and not treating the person needing to be rescued with the respect they deserve (p. 466). This possibilist (and seemingly Kantianesque) response on their part seems to be in tension with the arguments they made about sweatshops that appear actualist in nature. Moreover, their attempt at identifying a morally relevant difference between the rescue case and potentially analogous sweatshop cases is unconvincing (pp. 466-467). Sweatshop owners may also take advantage of their monopoly on the means of "rescue" (i.e. employment) and consequently exhort workers by paying them the bare minimum they can.

Fortunately, looks can be deceiving, and there needn't even be a tension in their arguments, or so we'll now

\footnotetext{
31 This is not strictly entailed by actualism, but it is entailed by actualism coupled with widely accepted axioms about moral blameworthiness. For more on this, see Timmerman and Swenson (2019).

32 This objection is raised in the literature by Ross (2013), Timmerman and Cohen (2016), and Zimmerman (2017, p. 121).

33 This case is structurally identical to the Bobby Knight example given in Norcross (2005, pp. 65-168).
}

suggest. Our criticisms notwithstanding, we understand Powell and Zwolinksi's desire to appeal to both actualism and possibilism in their arguments. Though, as formulated, these views are mutually exclusive, yet they both seem to be getting at an important truth. This is why the debate seems so paradoxical. Though, as we demonstrated in this section, each view seems to have implausible commitments as well. This appears to be bad news for the actualist and possibilist arguments in the literature. We believe each of these positions should be rejected. However, there may yet be hope for something like those positions. In the next section, we articulate and provide a prima facie defense of a form of hybridism, one which captures what seems compelling about both actualism and possibilism, yet which aims to avoid the implausible commitments of each.

\section{A Hybridist Approach to the Ethics of Sweatshops}

To correctly diagnose the problems with actualism and possibilism, we should start by recognizing that each view posits a single ought, and each of these oughts leads to seemingly unpalatable consequences in various actualist/possibilist (sweatshop) cases. In order to avoid these problems, then, a view will either need to posit a single ought that generates the correct verdicts in all actualist/possibilist cases or posit multiple oughts that together can generate the correct verdicts in actualist/possibilist cases. We are uncertain about the viability of the first option. Yet we are optimistic about the viability of the second option. In what follows, we defend our favored version of hybridism, referred to as single obligation hybridism, which posits two distinct moral "oughts," one actualist in nature and one possibilist in nature. ${ }^{34}$ Given the space available in this article, we do not aim to provide a decisive argument in favor of single obligation hybridism. Rather, our goal is to provide a defeasible argument for our favored view by illustrating how it can avoid the problems identified for actualism and possibilism. In doing so, we will also clarify its implications for the sweatshop debate, and rebut the most salient objections.

According to single obligation hybridism there are two moral oughts; one is the ought of moral obligation and the other is a practical moral ought, one that tells agents what to do in light of their moral shortcomings. Acting in accordance with this practical moral ought will minimize the number of wrong actions agents freely perform over the course of their life. These oughts will only diverge in cases in which an imperfect moral agent is disposed to perform a wrong action

\footnotetext{
${ }^{34}$ For ease of exposition, we will use the term hybridism to refer specifically to single obligation hybridism throughout the paper.
} 
in more than one counterfactual situation. To be sure, both oughts are moral oughts. It's just that one moral ought tracks moral obligation, while the other tracks how imperfect moral agents should act in order to minimize the amount of wrong actions they freely perform. ${ }^{35}$

Again, we cannot provide a complete defense of hybridism in this section, though we can provide the core of our defense in the space we have. ${ }^{36}$ Our more important goal in this section is to explore hybridism's implications for questions about the ethics of sweatshops. Stated briefly, hybridism provides reason to accept that certain exploitation arguments correctly identify owner's moral obligations with respect to sweatshops, but it also allows that such employers may have most practical moral reason to open sweatshops. In line with the so-called Reasonable View, consumers may be morally and practically permitted to purchase goods from sweatshops because that is the best outcome they can bring about. So, to put it a bit simplistically, one possible upshot of hybridism is that, morally speaking, the exploitation arguments track employers' moral obligations, while the non-worseness arguments (at least sometimes) track what employers ought morally to do in a practical sense. Finally, the Reasonable View tracks the employers' practical moral ought, and consumers' moral and practical obligations.

Now that we have provided a general overview of what is to come, we are in a position to get to the more detailed defense of our position. Single obligation hybridism may be formulated more precisely as follows. ${ }^{37}$

\footnotetext{
35 The terminology of a "moral practical ought" is a bit tricky, in part, because the phrase "practical ought" is used in different ways in the literature and, in part, because we are identifying a unique kind of moral practical ought. So, we want to take care to specify exactly how we are using the term. Both oughts in hybridism are moral oughts, and so both concern what an agent morally ought to do. The possibilist ought tells the agent which action is morally required of them at the time(s) in question. The actualist ought tells the agent which action will, at the time(s) in question, result in the least amount of moral wrongdoing over the course of their lives. Since these are both moral oughts, they are in the same domain as one another, and in a different domain what whatever non-moral oughts there are. Hybridism takes no stance about how to weigh the oughts in various domains, or in the role that these moral oughts play in determining what one has most reason, all things considered, to do.

${ }^{36}$ Hybridism has been defended at length in the literature. See Timmerman (2015), Timmerman and Cohen (2016), and Cohen and Timmerman (forthcoming).

37 We are using the term obligation narrowly as shorthand for moral obligation and the term ought broadly to refer to any claim about how one should act within any normative domain. So, a moral obligation is one type of moral ought, while a practical moral ought is another type of moral ought. We could also speak of what one prudentially ought to do, what one legally ought to do, and so on. This formulation of $\mathrm{SOH}$ is a simplified version of the one given in Timmerman and Cohen (2016, pp. 682-683). The simpler version of SOH suffices for the purposes of this paper, however, since none of our arguments hinge on the issues addressed in the more complex definition.
}

\section{Single Obligation Hybridism (SOH)}

(I) Possibilist Moral Obligation: At $t$ an agent $S$ has a possibilist moral obligation to $\varphi$ at $t^{\prime}$ iff $\varphi$-ing at $t^{\prime}$ is part of the best series of acts that $S$ can perform from $t$ to the last moment that $S$ can possibly perform an act.

(II) Actualist Practical Moral Ought: At $t$ an agent $S$ has most practical moral reason to $\varphi$ at $t^{\prime}$ iff $\varphi$-ing at $t^{\prime}$ is under $S$ 's control at $t$ and $\varphi$-ing at $t$ ' is either (i) identical to the maximally specific possibilist obligation that $S$ has at $t$, (ii) a rationally permissible supererogatory act, or (iii) is the least rationally impermissible, all things considered, act-set presently under $S$ 's control at $t$. There is an act-set that satisfies (iii) iff no act-set presently under $S$ 's control at $t$ satisfies conditions (i) or (ii).

While this definition of $\mathrm{SOH}$ is rather technical, the basic idea is quite simple, and can be illustrated by considering its applications in Entrepreneurial Eddie. As in the original version of the case, suppose that the act-sets Eddie can perform are ranked from best to worst as follows.

$\mathbf{X}-<$ Pay his workers a high wage and keep the factory open as long as it's profitable $>$.

$\mathbf{Y}-<$ Pay his workers a low wage and keep the factory open as long as it's profitable $>$.

$\mathbf{Z}-<$ Pay his workers a high wage and close the factory after 6 months $>$.

Suppose, again, that if Eddie were to freely decide to $<$ pay his workers a high wage $>$ he would later freely decide to $<$ close the factory after 6 months $>$ no matter what he intends to do at the time he decides to <pay his workers a high wage $>$.

In this case, hybridism entails that Eddie has a possibilist moral obligation to <pay his workers a high wage> and also to $<$ keep the factory open as long as it's profitable $>$. This is because the possibilist obligation, which picks out the criterion of right, holds that agents are obligated to perform each act that is part of the best series of acts they can perform over the course of their lives. The possibilist obligation can also serve to ground reactive attitudes. On plausible accounts of blameworthiness, Eddie can be blameworthy to the extent he culpably fails to pay his employees the high wage. This feature of the view allows hybridism to be immune from the Not Demanding Enough Objection and from the Bad Behavior Objection. It can also capture what proponents of exploitation arguments want to capture. In paying his employees such a low wage, Eddie is wrongfully exploiting his employees and can be morally criticizable for doing so. 
At the same time, hybridism is immune from the Worst Outcome Objection because only the actualist moral ought is action-guiding. The actualist practical moral ought prescribes performing the act that would result in the best outcome from among the set of acts presently under the agent's control. ${ }^{38}$ Sometimes this is identical with the possibilist obligation and sometimes it isn't. This practical moral ought then serves the purpose of minimizing wrongdoing in light of one's moral shortcomings. One should act in accordance with this ought insofar as one should care about minimizing the amount of wrongdoing they freely perform over the course of their life. ${ }^{39}$ So, in Entrepreneurial Eddie, hybridism entails that Eddie practically morally ought to $<$ pay his employees a low wage $>$ because, of all the outcomes under his present control, <paying his employees a low wage> will bring about the best outcome. This is because, no matter what Eddie's current intentions are, he will freely $\mathrm{Z}$ if he now < pays his employees a high wage $>$ and freely $\mathrm{Y}$ if he now < pays his employees a low wage $>.{ }^{40}$ In essence, hybridism tells Eddie to perform a wrong act now (i.e. pay his employees a low wage) in order to prevent himself from performing an even worse act later (i.e. closing the factory after 6 months, leaving everyone destitute). Stated over simplistically, hybridism tells people to act like actualists, even though they're obligated to act like possibilists.

The actualist ought feature of hybridism captures what proponents of the Reasonable View want to capture in their

\footnotetext{
38 We are not claiming that this is the sense of ought that actualists had in mind when formulating their view. They were indeed referring to the ought of moral obligation. Rather, we are only claiming that there is (defeasible) reason to accept the two oughts of hybridism, as we've formulated it, over either actualism or possibilism. Accepting hybridism avoids the three problems we've identified for other views, while retaining the elements that seem plausible about both actualism and possibilism, or so we argue.

39 We wish to note that hybridism does not assume the truth or falsity of moral rationalism, viz.- - the view that if one is morally obligated to $\varphi$, then they are rationally required to $\varphi$. If moral rationalism is true, and if one's practical moral ought conflicts with the ought of moral obligation, then it follows that acting in accordance with one's practical moral obligation will entail that one is doing something irrational. At the same time, in cases with this structure, the true counterfactuals of freedom will guarantee that acting in accordance with one's moral obligation will also entail that one will eventually acts irrationally. They need not act irrationally, but the true counterfactuals of freedom entail that they will freely choose to do so at some point. One of us is sympathetic to such a view for reasons given in Timmerman and Swenson (2019, § VII), but hybridism explicitly remains neutral with respect to this question. It is consistent with views that do, and don't, allow that doing what we morally ought to do can be irrational. We take this to be a feature, not a bug, of hybridism.

${ }^{40}$ For very helpful written and verbal feedback on earlier versions of this paper, we would like to thank Daniel Palmer, Geoffrey SayreMcCord, Kenneth Silver, and participants at the 2019 Philosophy, Politics, and Economics conference.
}

arguments. It also captures something like what proponents of the non-worseness principle want to capture in their arguments. That is, hybridism allows that in some sense it's often (though not always) better for sweatshop employers to pay their employees a low wage than not to and, as such, third parties should not attempt to prevent sweatshops from coming into existence. Furthermore, in line with both views, hybridism allows that consumers may permissibly purchase sweatshop goods.

To be sure, hybridism won't capture everything that proponents of the Reasonable View and non-worseness principle want to capture, and not all real life considerations will map on to various actualist/possibilist cases. Contrary to the Reasonable View, hybridism entails that the thing to do for sweatshop employers is to create sweatshops. Even though this is morally wrong, the alternative to them creating sweatshops is sometimes even worse. Notice this means that the Reasonable View is subject to the Worst Outcome objection. This consideration makes us think that it's the so-called Reasonable View, and not hybridism, that is in need of amendment. Contrary to defenders of the non-worseness principle, hybridism allows that it can be wrong for sweatshop employers to exploit their employees even though doing so can be the result of a voluntary, mutually beneficial transaction. At least, hybridism allows this given the ranking of outcomes we've provided above. We believe these rankings are plausibly the correct ones for reasons given by defenders of exploitation arguments. As such, we think defenders of the non-worseness principle should slightly revise their view to be consistent with both hybridism and the ranking of outcomes we've provided. However, we recognize that there is reasonable disagreement about the issue of how to rank the outcomes. This is not a problem for our argument, though, since hybridism can generate the verdicts in line with those defended by proponents of the non-worseness principle. To do this, one would simply need to provide a different ranking of the outcomes, one where $(\mathrm{Y} \geq \mathrm{X})$. We take this to be a feature, not a bug, of hybridism.

To sum up, hybridism captures what seems right about actualism and possibilism, while avoiding the problems that plague each view. This resolves the paradox of actualist/possibilist cases. It also supports what we take to be a plausible and heretofore overlooked view about the ethics of sweatshops. Specifically, hybridism allows that it's permissible for consumers to purchase goods from sweatshops, impermissible for employers to run sweatshops, even though this may be what they have most practical moral reason to do, and impermissible for third parties to prevent the existence of sweatshops when, and because, preventing the existence of sweatshops would bring about an even worse outcome. 


\section{Conclusion}

We have aimed to accomplish a few important goals with this paper. First, focusing on questions about the ethics of sweatshops, we brought to light the overlooked interdependence between the actualism/possibilism debate and the business ethics literature. In doing so, we examined some seminal arguments in the sweatshop literature and drew out their implicit actualist or possibilist assumptions. Second, we reviewed the problems that plague both actualism and possibilism and, as a consequence, the problems inherited by the arguments in the sweatshop literature that implicitly assume either actualism or possibilism. Third, we proposed and made a prima facie case for an alternative view known as single obligation hybridism. This form of hybridism retains what seems right about actualism and possibilism, yet avoids the problems that plague each view and, in our estimation, supports an extremely plausible set of verdicts about the ethics of sweatshops.

\section{Compliance with Ethical Standards}

Conflicts of interest The authors declare that they have no conflict of interest.

Informed consent Not applicable, as there was no empirical research conducted for this article.

Research Involving Human Participants and/or Animals None.

\section{References}

Arneson, R. (2013). Exploitation and outcome. Politics, Philosophy and Economics, 12, 392-412.

Arnold, D. (2001). Coercion and moral responsibility. American Philosophical Quarterly, 38, 53-67.

Arnold, D. (2003). Exploitation and the sweatshop quandary. Business Ethics Quarterly, 13, 243-256.

Arnold, D., \& Bowie, N. (2003). Sweatshops and respect for persons. Business Ethics Quarterly, 13(2), 221-242.

Arrington, R. (1982). Advertising and behavior control. Journal of Business Ethics, 1, 3-12.

Baker, D. (2012). Knowing yourself-And giving up on your own agency in the process. Australasian Journal of Philosophy, 90, 641-656.

Barnes, M. R. (2013). Exploitation as a path to development: Sweatshop labour, micro-unfairness, and the non-worseness claim. Ethics and Economics, 10, 26-43.

Bowie, N. (1999). Business ethics: A Kantian perspective. Hoboken, NJ: Wiley.

Bykvist, K. (2002). Alternative actions and the spirit of consequentialism. Philosophical Studies, 10, 45-68.

Cariani, F. (2016). Consequence and contrast in deontic semantics. Journal of Philosophy, 113, 396-416.

Carlson, E. (1995). Consequentialism reconsidered. Dordrecht: Kluwer.
Cohen, Y., \& Timmerman, T. (2016). Actualism has control issues. Journal of Ethics and Social Philosophy, 10, 1-18.

Cohen, Y. \& Timmerman, T. (forthcoming). Actualism, possibilism, and the nature of consequentialism. In D. Portmore (ed.), The Oxford handbook of consequentialism, Oxford University Press, NY.

Faraci, D. (2019). Wage exploitation and the nonworseness claim: Allowing the wrong, to do more good. Business Ethics Quarterly, 29(2), 169-188.

Ferguson, B. (2016). The paradox of exploitation. Erkenntnis, 81, 951-972.

Goldman, H.S. [now Holly M. Smith]. (1976). Dated rightness and moral imperfection. The Philosophical Review, 85, 449-487.

Goldman, H. S. [now Holly M. Smith]. (1978). Doing the best one can. In A. Goldman \& J. Kim (eds.), Value and morals: Essays in honor of William Frankena, Charles Stevenson, and Richard Brandt, (pp. 185-214). D. Reidel, Dordrecht, the Netherlands.

Herman, B. (2007). Moral literacy. Cambridge, MA: Harvard University Press.

Hill, T. (2002). Human welfare and moral worth: Kantian perspectives. NY: Clarendon Press.

Holley, D. (1998). Information disclosure in sales. Journal of Business Ethics, 17, 177-187.

Horton, J. (2017). The all or nothing problem. The Journal of Philosophy, 114, 94-104.

Horton, J. (2019). The exploitation problem. The Journal of Political Philosophy, 27(4), 469-479.

Jackson, F. (2014). Procrastinate revisited. Pacific Philosophical Quarterly, 95, 634-647.

Jackson, F., \& Pargetter, R. (1986). Ought, options, and actualism. The Philosophical Review, 95, 233-255.

Kagan, S. (2011). Do I make a difference? Philosophy and Public Affairs, 39, 105-141.

Kates, M. (2015). The ethics of sweatshops and the limits of choice. Business Ethics Quarterly, 25, 191-212.

Kiesewetter, B. (2015). Instrumental normativity: In defense of the transmission principle. Ethics, 125(4), 921-946.

Kiesewetter, B. (2018). Contrary-to-duty scenarios, deontic dilemmas, and transmission principles. Ethics, 1(October), 98-115.

Maitland, I. (1996). The great non-debate over international sweatshops. In T. Beauchamp \& N. Bowie (Eds.), Ethical theory and business. Upper Saddle River, NJ: Prentice Hall.

Maitland, I. (2001). Distributive justice in firms: Do the rules of corporate governance matter? Business Ethics Quarterly, 11, 129-143.

Malmqvist, E. (2013). Taking advantage of injustice. Social Theory and Practice, 39, 557-580.

Malmqvist, E. (2017). Better to exploit than to neglect? International clinical research and the non-worseness claim. Journal of Applied Philosophy, 34, 474-488.

Mayer, R. (2003). Payday loans and exploitation. Public Affairs Quarterly, 17, 197-217.

Mayer, R. (2007). Sweatshops, exploitation, and moral responsibility. Journal of Social Philosophy, 38, 605-619.

McMahan, J. (2018). Doing good and doing the best. In P. Woodruff (Ed.), The ethics of giving: Philosophers' perspectives on philanthropy (pp. 78-103). New York: Oxford University Press.

Meyers, C. (2004). Wrongful beneficence: exploitation and third world sweatshops. Journal of Social Philosophy, 35, 319-333.

Meyers, C. (2007). Moral duty, individual responsibility, and sweatshop exploitation. Journal of Social Philosophy, 38, 620-626.

Miller, J. (2003). Why economists are wrong about sweatshops and the anti-sweatshop movement. Challenge, 46, 93-122.

Moriarty, J. (2009). How much compensation can CEOs permissibly accept? Business Ethics Quarterly, 19, 235-250. 
Nefsky, J. (2011). Consequentialism and the problem of collective harm: A reply to Kagan. Philosophy and Public Affairs, 39, 364-395.

Norcross, A. (2005). Harming in context. Philosophical Studies, 123, $149-173$

Portmore, P. (2011). Commonsense consequentialism. New York, NY: Oxford University Press.

Portmore, P. (2019). Opting for the best: Oughts and options. New York, NY: Oxford University Press.

Powell, B., \& Zwolinski, M. (2012). The ethical and economic case against sweatshop labor: A critical assessment. Journal of Business Ethics, 107, 449-472.

Pummer, T. (2019). All or nothing, but if not all, next best or nothing. The Journal of Philosophy, 116(5), 278-291.

Radin, T., \& Calkin, M. (2006). The struggle against sweatshops: Moving toward responsible global business. Journal of Business Ethics, 66, 261-272.

Ross, J. (2013). Actualism, possibilism and beyond. Oxford Studies in Normative Ethics, 2, 74-96.

Sample, R. (2003). Exploitation, what it is and why it is wrong. Lanham, MD: Rowman and Littlefield.

Snyder, J. (2008). Needs exploitation. Ethical theory and moral practice, 11(389), 405

Snyder, J. (2009). What's the matter with price gouging? Business Ethics Quarterly, 19, 275-293.

Snyder, J. (2010). Exploitation and sweatshop labor: Perspectives and issues. Business Ethics Quarterly, 20, 187-213.

Sobel, J. H. (1976). Utilitarianism and past and future mistakes. Noûs, $10,195-219$.

Stegman, M. (2007). Payday lending. Journal of Economic Perspectives, 21, 169-190.

Steiner, H. (1984). A liberal theory of exploitation. Ethics, 94, 225-241.

Timmerman, T. (2015). Does scrupulous securitism stand-up to scrutiny? Two problems for moral securitism and how we might fix them. Philosophical Studies, 172, 1509-1528.

Timmerman, T. (2016). Your death might be the worst thing to ever happen to you (but maybe you shouldn't care). Canadian Journal of Philosophy, 46, 18-37.

Timmerman, T. (2019). Effective altruism's under specification problem. In H. Greaves \& T. Pummer (Eds.), Effective altruism: Philosophical issues (pp. 166-183). Oxford: Oxford University Press.
Timmerman, T., \& Cohen, Y. (2016). Moral obligations: Actualist, possibilist, or hybridist?". Australasian Journal of Philosophy, 94, 672-686.

Timmerman, T., \& Cohen, Y. (2019). Actualism and possibilism in ethics. In E. Zalta (ed.), The Stanford Encyclopedia of Philosophy, https://plato.stanford.edu/archives/sum2019/entries/actua lism-possibilism-ethics.

Timmerman, T., \& Swenson, P. (2019). How to be an actualist and blame people. In D. Shoemaker (Ed.), Oxford studies in agency and responsibility (pp. 216-241). Oxford: Oxford University Press.

Valdman, M. (2008). Exploitation and injustice. Social Theory and Practice, 34, 551-572.

Valdman, M. (2009). A theory of wrongful exploitation. Philosopher's Imprint, 9, 1-14.

Vorobej, M. (2000). Prosaic possibilism. Philosophical Studies, 97, 131-136.

Wertheimer, A. (1999). Exploitation (revised ed.). Princeton, NJ: Princeton University Press.

Woodard, C. (2009). What's wrong with possibilism. Analysis, 69 , 219-226.

Zakhem, A. (2008). Stakeholder management capability: A discoursetheoretical approach. Journal of Business Ethics, 79, 395-405.

Zimmerman, M. (1996). The concept of moral obligation. Cambridge: Cambridge University Press.

Zimmerman, M. (2006). The relevant risks to wrongdoing. In K. McDaniel, J. Raibley, R. Feldman, \& M. Zimmerman (Eds.), The good, the right, life and death: Essays in honor of Fred Feldman (pp. 151-172). New York, NY: Ashgate.

Zimmerman, M. (2017). Prospective possibilism. Journal of Ethics, $21,117-150$.

Zwolinski, M. (2007). Sweatshops, choice, and exploitation. Business Ethics Quarterly, 17, 689-727.

Zwolinski, M. (2008). The ethics of price gouging. Business Ethics Quarterly, 18(3), 347-378.

Publisher's Note Springer Nature remains neutral with regard to jurisdictional claims in published maps and institutional affiliations. 